\title{
METODOLOGIAS ATIVAS UTILIZADAS NO CURSO DE FARMÁCIA
}

\author{
Francielly de Jesus Sousa ${ }^{1}$ \\ Lorena Alves da Silva ${ }^{2}$ \\ Aline de Sousa Brito ${ }^{3}$ \\ Daniela Borges Marquez Barbosa ${ }^{4}$
}

Resumo: O emprego do uso de tecnologias na educaçáo tem promovido um impacto e grandes transformaçóes. As práticas tradicionais ainda são utilizadas com frequência, mas surge alternativas como as metodologias ativas que possibilitam uma construçáo e abordagem diferente do conhecimento. $\mathrm{O}$ objetivo deste artigo é descrever as aplicaçóes de metodologias ativas no ensino do curso de Farmácia. Foi realizada uma revisão bibliográfica em bases de dados como Scielo, Lilacs e Pubmed, bem como, no banco de dissertação e legislaçóes brasileiras, com coleta de dados entre os meses de março e junho de 2020. Alguns pontos podem ser limitantes para a utilização das metodologias ativas como a imersão do aluno no contexto e a formação de profissionais que irão atuar com esses alunos. Contudo, é possível perceber um melhor envolvimento dos alunos e o compartilhamento de experiências enriquecedoras. As metodologias ativas têm se tornado uma realidade no Brasil, sendo vivenciada em todos os níveis da educaçáo brasileira e que geram uma preocupação com o processo de transição e adaptação de todos os atores envolvidos, professores e estudantes, bem como as instituiçôes educacionais.

Palavras-chave: Educação em Farmácia, Farmácia, Docentes de Farmácia.

1 Discente em Farmácia pela Universidade Salgado de Oliveira.

2 Discente em Farmácia pela Universidade Salgado de Oliveira.

3 Mestre em Assistência e Avaliação em Saúde pela Universidade Federal de Goiás (UFG), Docente do curso de Farmácia pela Universidade Salgado de Oliveira (UNIVERSO) - Goiânia, e-mail: aline_sbrito@yahoo.com.br.

4 Mestre em Ciências Farmacêuticas pela Universidade Federal de Goiás (UFG), Docente do curso de Farmácia pela Universidade Salgado de Oliveira (UNIVERSO) - Goiânia e do curso de Estética da Universidade Paulista (UNIP), e-mail: daniela_bmb@yahoo.com.br. 


\title{
ACTIVE METHODOLOGIES USED IN THE PHARMACY COURSE
}

\begin{abstract}
The use of technology in education has had an impact and major transformations. Traditional practices are still used frequently, but there are alternatives such as active methodologies that enable a different construction and approach to knowledge. The purpose of this article is to describe the applications of active methodologies in the teaching of the Pharmacy course. A bibliographic review was carried out in databases such as Scielo, Lilacs and Pubmed, as well as in the dissertation and Brazilian legislation database, with data collection between the months of March and June 2020. Some points can be limiting for the use of active methodologies such as immersing the student in the context and training professionals who will work with these students. However, it is possible to perceive better student involvement and the sharing of enriching experiences. Active methodologies have become a reality in Brazil, being experienced at all levels of Brazilian education and that generate a concern with the transition and adaptation process of all involved actors, teachers and students, as well as educational institutions.
\end{abstract}

Keywords: Pharmacy Education, Pharmacy and Pharmacy Teachers.

\section{INTRODUÇÃO}

$\mathrm{O}$ ensino nos cursos superiores, enfrentam desafios em alinhar os conhecimentos e aprendizado acadêmico com as mudanças crescentes que acontecem na sociedade e no mercado de trabalho, essa junção resulta na inserção dos profissionais no mercado, e os torna mais capacitados para se adequarem às transformaçōes (AMARAL; JUNIOR, 2016).

A área da saúde tem mostrado caminhos para métodos inovadores para a formação e capacitação profissional, onde são inseridos em aspectos técnicos, éticos e políticos para mudanças em processos de trabalho enraizados em condutas padronizadas, fragmentadas do cuidado, o que torna um desafio para as políticas públicas do Sistema Único de Saúde (SUS). Dessa forma novas formas de ensinoaprendizagem são adquirida na organização curricular das disciplinas e profissóes na área da saúde, de modo a integrar teoria e prática, ensino e serviço, e ainda fazer com que o acadêmico desenvolva a capacidade de reflexáo sobre problemas enfrentados no cotidiano e formule meios de ação próprios, que sejam capazes de trazer mudanças para a realidade atual (MARIN, et al., 2010).

No curso de farmácia, o ensino passa por uma crise na busca de mudança conceitual de novos padróes de ensino devido a uma insatisfaçáo com modelos tradicionais. Nesse contexto, é necessário um novo perfil do docente e também do discente. A utilização das metodologias ativas em sala de aula devem aliar a educação como um todo e não só o ensino, é necessário atualizar os conhecimentos, criar questionamentos construtivos e práticas diferenciadas (SILVA; MIGUEL; TEIXEIRA, 2011).

Com as novas práticas de metodologia ativa dentro do curso de farmácia, permite o professor elaborar estratégias para o aperfeiçoamento do aluno, sendo assim necessário ambos: observar, escutar, acompanhar, registrar, discutir, comparar, intervir, mudar e melhorar continuamente (LIMBERGER, 2013). 
Ao se trabalhar com esse tipo de metodologia, se favorece a contextualização dos conteúdos disciplinares, o estudante parte de uma ponderação sobre a sua visão de mundo e começa a interpretar outras visóes, numa aprendizagem com mais significado (GHEDIN, 2012; BRITO et al., 2019).

A mudança é constante, e a educação de novos farmacêuticos necessita de reformulaçóes, com novos profissionais formados adequados às necessidades da saúde da população. O estudante constrói seu conhecimento de maneira ativa através de novas metodologias de ensino e aprendizagem, o futuro profissional é convidado a trabalhar com problemas reais, que assumi responsabilidades e interage com a população e os profissionais de saúde de outras áreas (LIMBERGER, 2013)

Este novo profissional tem sido exigido pelas últimas reformas curriculares dos cursos da área de saúde, e em específico, do curso de Farmácia, como um profissional que deve ter o perfil mais crítico e reflexivo para atuar em todos os níveis de atenção à saúde (BRASIL, 2002).

O objetivo desse artigo é descrever as aplicaçóes de metodologias ativas no ensino do curso de Farmácia.

Foi realizada uma revisão bibliográfica narrativa descritiva, sobre as metodologias ativas utilizadas em instituiçóes de ensino do Brasil principalmente no curso de Farmácia. Os dados foram coletados entre os meses de março e junho de 2020. As pesquisas foram feitas com a utilização dos seguintes Descritores em Ciências da Saúde (DeCS): Educação em Farmácia, Farmácia e Docentes de Farmácia; nas bases de dados: Biblioteca Virtual de Saúde (BVS), Literatura LatinoAmericana e do Caribe em Ciências da Saúde (LILACS), Scientific Electronic Library Online (Scielo), United States National Library of Medicine (Pubmed), no banco de dissertação e legislações brasileiras publicadas no período de 1998 a 2020.

Os critérios de inclusão para a elaboração do artigo foram: artigos publicados em periódicos indexados nas bases eletrônicas citadas acima, publicados nos idiomas português, inglês ou espanhol e que abordam a utilização de metodologias ativas na área da saúde e no curso de Farmácia em instituiçôes de ensino do Brasil e legislaçóes brasileiras pertinentes ao tema proposto. Desse modo, artigos não pertinentes ao tema foram excluídos deste estudo.

Depois de selecionados os artigos, foi feita uma leitura criteriosa dos artigos na integra e selecionados os que melhor se adequava aos critérios acima, foram utilizados 23 artigos e em seguida realizado a redação.

\section{DESENVOLVIMENTO}

A partir das décadas de 80 e 90 o sistema de saúde no Brasil apresentou várias mudanças e a principal foi a criaçáo do Sistema Único de Saúde (SUS), impulsionando fortes transiçóes no ensino em saúde com a finalidade de atender uma demanda de profissionais com um novo perfil. $\mathrm{O}$ ensino farmacêutico também acompanhou essa evolução, passando a formar profissionais generalistas, menos tecnicistas e mais aptos a interagirem com a equipe multiprofissional, com o 
paciente, voltado para a gestáo farmacêutica. Com essa demanda diferente do ensino em saúde surgem as metodologias ativas com o intuito de melhorar a formação e qualificar profissionais dentro de um perfil que rompe com métodos tradicionais, mais voltados para a interdisciplinaridade, interação dos acadêmicos e também uma maior autonomia no ensino/aprendizagem (BRITO, 2018).

As metodologias ativas disponíveis são várias e podem ser aplicadas na aprendizagem de todos os níveis de ensino, porém é necessário saber escolher a que melhor se adapta a etapa que o aluno está cursando. Nos primeiros semestres, melhor se adequa simulaçóes, discussóes em sala de aula, dramatizaçóes, mapas conceituais e mentais. Nos semestres intermediários e finais, a utilizaçáo de metodologias de problematizaçáo, estudo de caso e aprendizagem baseada em projetos, mostram se eficazes para formação do aluno (LIMBERGER, 2013 apud OLIVEIRA 2010).

Segundo Moran (2015) as metodologias aplicadas devem caminhar junto com o resultado que se objetiva chegar. Como por exemplo, para que o aluno seja proativo é necessário a utilização de metodologias que envolva complexidade, que faça com que pense e reflita, que o faça tomar decisóes e busque resultados e soluçôes, com uso de matérias relevantes. Para despertar a criatividade, se faz necessárias metodologias em que o discente tenha experiências de várias possibilidades de mostrar iniciativa. Quanto mais próximo da realidade for o método de ensino melhor, dando assim início a uma busca, para alcançar diversas áreas de conhecimento e reconstrução de novas práticas.

Essas metodologias são norteadas por algumas características, tais como: aluno no centro do processo, aluno com autonomia, professor como mediador, facilitador e ativador, problematizaçáo da realidade, reflexão e trabalho em equipe (Figura 1). Essas características devem ser atreladas as práticas pedagógicas e se inter-relacionarem, não pode se separar quando aplicado o método ativo em sala de aula (DIESEL; MARCHESAN; MARTINS, 2016).

Figura 1 - Características das metodologias ativas de ensino

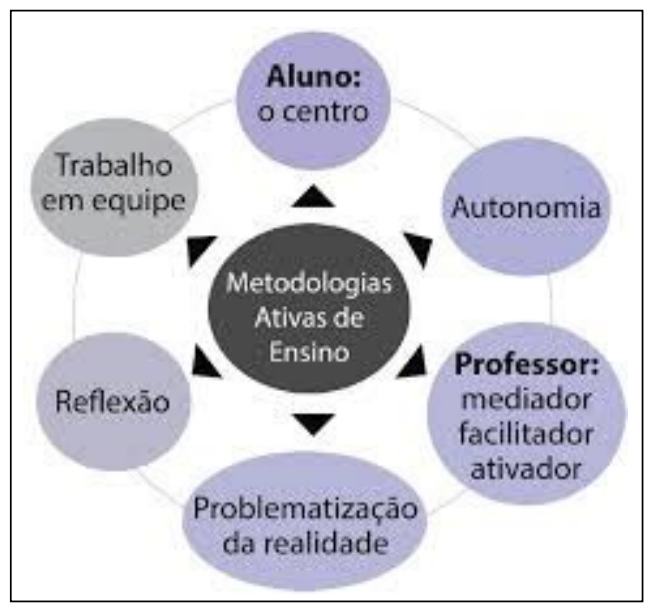

Fonte: Diesel, Marchesan e Martins (2016) 
Moraes e Castellar (2018) relatam que quando se trata de metodologias ativas está se afirmando que o estudo através da investigação, teatro, uso de tecnologias, trabalho de campo, aulas cooperativas entre outros vários tipos, são métodos que colocam o aluno no centro do processo de aprendizagem, portanto são exemplos de Metodologias Ativas. Aquelas que utilizam métodos, como ler um texto ou observar um professor fazer algo são consideradas um método de ensino passivo.

A Metodologia Ativa pode ser caracterizada por suas variaçóes, em que se destacam os modelos didáticos e técnicas de aprendizagem, denominados: Aprendizagem por Problemas (PBL/ABP), Estudo de Caso, Projetos de Integraçáo e Técnica da Problematização (PEREIRA, 2012). Nessa revisão será abordado as Metodologias ativas: Problematização, Aprendizagem Baseada em Problemas, Aprendizagem Baseada em Jogos e Aprendizagem Baseada em Tarefas.

\section{a. Problematizaçáo baseada no Arco de Charles Maguerez}

A Metodologia da Problematização com o arco de Maguerez é uma metodologia baseada na concepçáo de que a aprendizagem acontece a partir da realidade física, psicológica ou social. A realidade é tida como o problema, ou seja, é algo a ser solucionado ou melhorado. Essa metodologia faz com que a educação transforme o aluno e seu grupo enquanto tentam mudar a realidade (BERBEL; GAMBOA, 2011).

O Arco de Maguerez é composto por cinco etapas: observação da realidade (problema), determinação de pontos chaves, teorização, hipóteses de solução e aplicaçáo à realidade (Figura 2).

Figura 2 - Esquema do Arco de Maguerez

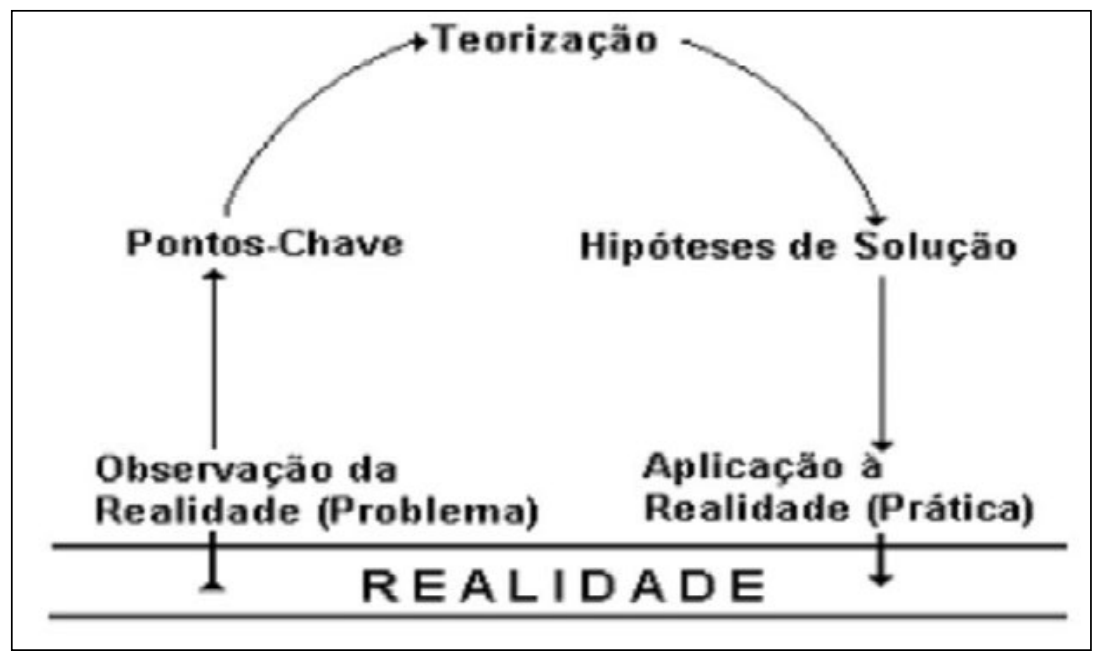

Fonte: Berbel e Gomboa 2011. 
A problematização permite que o sujeito passe por alguns caminhos que o levam a uma reflexão da situação como um todo de uma realidade sólida, prática e complexa, está presente nesse processo o exercício da praxis e a possibilidade de formação da consciência da práxis (BERBEL, 1998).

Machareth e Messeder (2018) relata um estudo realizado para a produção de uma revista digital que aborda os principais erros encontrados em medicina laboratorial. Para a construçáo dessa revista os alunos do curso de Farmácia da IFRJ-Realengo da disciplina de Estágio 111 em Análises Clínicas aplicaram o Arco de Charles Maguerez para solucionarem os problemas encontrados nos locais de estágios. O estudo por meio do arco, possibilitou que os acadêmicos fizessem uma análise mais criteriosa e reflexiva sobre o assunto abordado, além de fazerem também um planejamento esquematizado sobre os resultados obtidos. Essa metodologia contribui de diversa formas, proporciona experiências de situaçôes reais, deram autonomia na formaçáo do conhecimento. Além de concluírem também que o método pode ser significativo em outras áreas da saúde.

\section{b. Aprendizagem Baseada em Problemas}

A metodologia de Aprendizagem baseada em Problemas (ABP) é um método essencialmente de aprendizagem baseado em problemas enfrentados na realidade, podendo ser reais ou fictícios. Se baseia em processos que o ensino não é receptivo passivo, acumulativo de informaçôes e sim na construção de conhecimento. Entretanto os problemas da $\mathrm{ABP}$ devem condizer com o nível cognitivo/motor/ afetivo do aluno, deve desafiar o estudante, mas sem frustrar sua capacidade de solucionar os problemas proposto (FILHO; RIBEIRO, 2009).

ABP foi utilizada no curso Farmácia do Centro Universitário do Norte Paulista (UNORP), na disciplina de Bioquímica. A metodologia foi aplicada no tema metabolismo dos carboidratos, que inicialmente foram realizadas palestras curtas e objetivas sobre o conteúdo teórico. Após esse período, os alunos foram divididos em grupos tutoriais para a resoluçáo de questóes contextualizadas. $\mathrm{O}$ professor direcionou as discussôes para a elucidas das questôes propostas. Ao final, conclui-se que nessa metodologia o principal responsável pela aprendizagem é o próprio aluno, observou-se um aumentou do interesse em aprender e melhorou as discussóes de estudos de casos em grupo. Essa contextualização das questóes estabeleceu uma aproximação entre a teoria e a prática profissional (COVIZZI; ANDRADE, 2012).

\section{c. Aprendizagem Baseadas em Jogo}

Os jogos são um tipo de metodologia bem aceita por geraçôes que são acostumadas a jogar. Jogos que envolva cooperação ou individuais, de concorrência e auxilio, com estratégias, níveis, capacidades e agilidades de forma bem definida é um método de ensino cada vez mais presente em diversas áreas e níveis de ensino (MORAN, 2015). 
Metodologias baseadas em jogos são uma ferramenta de grande valia, pois despertam o entusiasmo dos alunos, é uma maneira divertida e ao mesmo tempo interativa de aprender, que resulta em conhecimentos significativos. Os jogos proporciona aos discentes experiências diversas pessoal e social, colabora na formação de novas descobertas, no crescimento intelectual, ao mesmo tempo faz com que o professor seja o mediador, que estimula e avalia o conteúdo de ensino, leva assim os alunos ao conhecimento científico, que os fazem buscarem, mesmo que de forma virtual, soluçóes para problemas enfrentados no dia a dia (CAMPOS; BORTOLOTO; FELÍCIO, 2003).

$\mathrm{O}$ uso da metodologia baseada em jogos possibilita também a interação de diversas áreas de conhecimento que possuem disciplinas em comum. O que pode resultar em uma ampliaçáo considerável na relação do homem com o mundo, objetividade e subjetividade, ciência e tecnologia entre outros (KESSLER, 2010).

O método foi aplicado em forma de "Gincana", para alunos do curso de Farmácia, na modalidade presencial e a distância (gincana virtual). Foi desenvolvida em 2012 na disciplina de Atenção Farmacêutica II, do Curso de Farmácia da Universidade Federal do Rio Grande do Sul. Para realização deste estudo, a "Gincana" foi aplicada na modalidade a distância no primeiro semestre de 2012 e na modalidade presencial no segundo semestre do mesmo ano (GOSSENHEIMER; CARNEIRO; CASTRO, 2015).

O tema da "Gincana" era sobre os conteúdos que haviam sido trabalhados no semestre na modalidade presencial a classe foi separada em equipes que deveria criar três tipos de tarefas de cada (Jogo dos sete erros, Jogo de Adivinhação, Mímica e Palavras cruzadas). Tudo era avaliado pelos professores, em seguida era trocado as tarefas entre os grupos e resolviam durante o período da aula (GOSSENHEIMER; CARNEIRO; CASTRO, 2015).

A "Gincana” virtual seguia o mesmo princípio da presencial, foi utilizado uma plataforma virtual, Moodle, com um sistema de gerenciamento, as equipes foram divididas e somente a equipe tinha acesso as publicaçôes do grupo. A metodologia promoveu um aumento da atenção e concentração dos estudantes por conta da competição. A modalidade presencial apresentou melhores resultados, a modalidade virtual diminui a interação entre os participantes, porém incentiva a participação do aluno devido a exposiçấo ser menor (GOSSENHEIMER; CARNEIRO; CASTRO, 2015).

\section{d. Aprendizagem Baseada em Tarefas}

A Aprendizagem Baseada em Tarefas (ABT) ou team based learning (TBL) é uma metodologia de ensino que tem como objetivo o ensino de forma simultâne a de equipes em uma mesma sala baseada na discussão de situaçóes problemas. Além de estimular a curiosidade do aluno a partir da compreensão do objeto de estudo, e não da sua memorização ou transferência de conhecimentos (MICHAELSEN, 2004). 
Essa metodologia foi utilizada e avaliada nas Faculdades Integradas Maria Imaculada em Mogi Guaçu no estado de São Paulo no curso de Farmácia na disciplina de Farmacologia. Essa metodologia promoveu a motivaçáo para o aprendizado, o desenvolvimento do raciocínio lógico e aplicado, assim como a estruturação do conhecimento em situaçóes reais da profissão e o desenvolvimento de habilidades necessárias para a atuação do farmacêutico no mercado de trabalho (MARINI,2013).

\section{Conclusáo}

A metodologia ativa de ensino tem demonstrado que é uma ferramenta muito importante para o desenvolvimento e a formação acadêmica do futuro profissional farmacêutico. Essa metodologia proporciona ao acadêmico a possibilidade de discutir em grupo, de formular suas próprias conclusóes e com isso auxilia na formação de profissionais que terão a consciência de respeitar opinióes e posiçóes diferentes.

Com base nesses estudos encontrados é possível perceber que essas metodologias já estão sendo utilizadas nos cursos de farmácia no Brasil, e devido a diversidade de metodologias é possível selecionar a metodologia ativa que mais atenda às necessidades e particularidades de cada disciplina.

Contudo existem vários desafios que devem ser enfrentados por gestores, docentes e alunos, afinal são muitas dúvidas a respeito dos conceitos e aplicaçôes das metodologias, suas potencialidades e limitações em cada disciplina.

\section{REFERÊNCIAS}

AMARAL, W. A. N.; JUNIOR, F. G. S. Uso da metodologia CANVAS em processos de ensino e aprendizado em Engenharia Florestal e Gestão Ambiental. Anais do 2o

Congresso de Graduaçáo da Universidade de Sáo Paulo, São Paulo, p. 31, jul. 2016. Disponível em <https://www.prg.usp.br/2o-congresso-de-graduacao/> acesso em 29 de maio de 2020.

BERBEL, N. A. N. A problematização e a aprendizagem baseada em problemas: diferentes termos ou diferentes caminhos? Interface - Comunicaçáo, Saúde,

Educação, Botucatu, v.2, n.2, fev. 1998. Disponível em: < https://www.scielo.br/scielo. php?pid=S1414-32831998000100008\&script=sci_arttext\&tlng=pt $>$ acesso em 29 de maio de 2020.

BERBEL, N. A. N. As metodologias ativas e a promoção da autonomia de estudantes. Semina: Ciências Sociais e Humanas, Londrina, v. 32, n. 1, p. 25-40, jan./jun. 2011. Disponível em: <http://dx.doi.org/10.5433/1679-0383.2011v32n1p25> acesso em 29 de maio de 2020.

BERBEL, N. A. N.; GAMBOA, S. A. S. A metodologia da problematização com o Arco de Maguerez uma perspectiva teórica e epistemológica. Filosofia e Educaçáo, 
v. 3, n. 2, Out. 2011/ mar. 2012. Disponível em: http://repositorio.minedu.gob.pe/ handle/123456789/2846> acesso em 29 de maio de 2020.

BRASIL. Ministério da Educação. Resolução CNE/CES n. 2, de 19 de fevereiro de 2002. Institui Diretrizes Curriculares Nacionais do Curso de Graduação em Farmácia. Brasília: MEC, 2002.

BRITO, A. S. Desenvolvimento e validaçáo de uma matriz de competências para cursos de farmácia. 2018. 150 f. Dissertação (Mestrado em Assistência e Avaliação em Saúde) - Universidade Federal de Goiás, Goiânia, 2018.

BRITO, A. S.; SILVA, C. B.; GARCIA, T. A.; GALATO, D.; LOPES, F. M. Desafios, possibilidades e limitações do ensino por competências na área da saúde. In: LOPES, F. M; SANTOS, R, S. Ensino, assistência e avaliaçáo de tecnologias na saúde. 1.ed. Curitiba: Brazil Publishing, 2019. p. 28 - 46. E-book.

CAMPOS, L. M. L. BORTOlOTO, T. M.; Felício, A. K. C. A Produção de Jogos Didáticos para o Ensino de Ciências e Biologia: Uma Proposta para Favorecer a Aprendizagem. Cadernos dos Núcleos de Ensino, São Paulo, Brasil. p. 35- 48. 2003.

COVIZZI, U.D.S.; ANDRADE, L. P.F. Estratégia para o ensino do metabolismo dos carboidratos para o curso de farmácia, utilizando metodologia ativa de ensino. Revista Brasileira de Ensino de Bioquímica e Biologia Molecular, n. 1, 2012.

DIESEL, A.; MARCHESAN, M. R.; MARTINS, S. N. Metodologias ativas de ensino na sala de aula: um olhar de docentes da educação profissional técnica de nível médio. Revista Signos, Lajeado, ano 37, n. 1, p. 153-169, 2016. Disponível em: <http:// univates.br/revistas/index.php/signos/article/view/1008> acesso em 29 de maio de 2020.

FILHO, E. E.; RIBEIRO, L. R. C. Aprendendo com PBL -aprendizagem baseada em problemas: relato de uma experiência em cursos de engenharia da EESC-USP. Revista Minerva, v. 6, n.1, p. 23-30. 2009.

GOSSENHEIMER, A. N.; CARNEIRO, M. L. F.; CASTRO, M. S. Estudo comparativo da metodologia ativa "gincana" nas modalidades presencial e à distância em curso de graduação de Farmácia. Revista ABCS Health Sciences, v.40, no 3, p. 234-240, ago./dez. 2015. Disponível em: <https://doi.org/10.7322/abcshs.v40i3.801> acesso em 29 de maio de 2020.

GHEDIN, E. Teorias Psicopedagogicas do Ensino Aprendizagem. Boa Vista: UERR Editora, 2012.

KESSLER, M. C.; PAULA, C. G.; ALBÉ, M. H.; MANZINI, N..; BARCELLOS, C.; CARLSON, R.; MARCON, D.; KEHL, C. Impulsionando a aprendizagem na universidade por meio de jogos educativos digitais. Simpósio Brasileiro de Informática na Educaçáo, 2010. Disponível em: <https://www.br-ie.org/pub/index.php/sbie/article/ view/1462> acesso em 29 de maio de 2020. 
LIMBERGER, J. B. Metodologias ativas de ensino-aprendizagem para educação farmacêutica: um relato de experiência. Interface comunicação e saúde, v.17, n.47, p.969-975, out./dez. 2013. Disponível em: < https://www.scielo.br/scielo. php?pid=S1414-32832013000400020\&script=sci_abstract\&tlng=pt $>$ acesso em 29 de maio de 2020.

MACHARETH, S.; MESSEDER, J. C. Metodologia da problematização em um curso de Farmácia: produção de uma revista digital sobre erros laboratoriais. Arquivos do Mudi, v.22, n. 1, p. 17-32, mai. 2018. Disponível em: <http://periodicos.uem.br/ojs/index.php/ ArqMudi/article/view/40447> acesso em 29 de maio de 2020.

MARIN, M. J. S.; LIMA, E. F. G.; PAVIOTTI, A. B.; MATSUYAMA, D. T.; SILVA, L. K. D.; GONZALEZ, C.; DRUZIAN, S.; ILIAS, M. Aspectos das fortalezas e fragilidades no uso das Metodologias Ativas de Aprendizagem. Revista brasileira de educação médica, Rio de Janeiro, v.34. n.1, p.13 - 20, Jan/Mar, 2010. Disponível em: <https://doi. org/10.1590/S0100-55022010000100003 > acesso em 29 de maio de 2020.

MARINI, D. C. Avaliação da Experiência de estudantes de Farmácia no Componente Curricular de Farmacologia com a utilização da Metodologia de Aprendizagem Baseada em Tarefas. FOCO, v. 4, n. 5, p. 89-109, 2013.

MICHAELSEN, L. K; KNIGHT, A. B.; FINK, L. D. Team-based learning: A Transformative use of Small Groups in College Teaching. Virginia: Stylus Publishing, 2004.

MORAES, J. V.; CASTELLAR, S. M. V. Metodologias ativas para o ensino de Geografia: um estudo centrado em jogos. Revista Electrónica de Enseñanza de las Ciências. v. 17, n. 2, p. 422-436, 2018. Disponível em: <http://reec.webs.uvigo.es/volumenes/ volumen17/REEC_17_2_07_ex1324.pdf> acesso em 29 de maio de 2020.

MORAN, J. Mudando a educação com metodologias ativas. Coleção Mídias Contemporâneas. Convergências Midiáticas, Educaçáo e Cidadania: aproximaçóes jovens. São Paulo, vol. 2, p. 15-33, 2015. Disponível em: <https://www.ucs.br/site/midia/ arquivos/bibliografia-PGCIMA-canela.pdf> acesso em 29 de maio de 2020.

PEREIRA, R. Método Ativo: Técnicas de Problematização da Realidade aplicada à Educação Básica e ao Ensino Superior. VI Colóquio Internacional "Educaçáo e Contemporaneidade”. Sergipe, 20 a 22 de setembro 2012. Disponível em: < http:// educonse.com.br/2012/eixo_17/pdf/46.pdf> acesso em 29 de maio de 2020.

SILVA, R. H. A.; MIGUEL, S. S.; TEIXEIRA, L. S. Problematização como método ativo de ensino-aprendizagem: estudantes de farmácia em cenários de prática. Trabalho Educação e Saúde, Rio de Janeiro, v. 9 n. 1, p. 77-93,mar./jun.2011. Disponível em: < https:/www.scielo.br/scielo.php?pid=S1981-77462011000100006\&script=sci_arttext $>$ acesso em 29 de maio de 2020. 